\title{
MULHERES, ECOFEMINISMO E DESENVOLVIMENTO SUSTENTÁVEL: UM ESTUDO DE CASO DIANTE DA PERSPECTIVA DA SUSTENTABILIDADE E DA SOCIEDADE EM REDE
}

WOMEN, ECOFEMINISM AND SUSTAINABLE DEVELOPMENT: A CASE

STUDY BEFORE THE SUSTAINABILITY AND NETWORK SOCIETY

PERSPECTIVE

\author{
Bianca Larissa Soares de Jesus Roso ${ }^{\mathrm{I}}$ \\ Angela Araujo da Silveira Espindola ${ }^{\text {II }}$
}

${ }^{\mathrm{I}}$ Universidade Federal de Santa Maria, Santa Maria, RS, Brasil. Mestranda em Direito. E-mail: biancasoaresroso@gmail. com

${ }^{\text {II }}$ Universidade Federal de Santa Maria, Santa Maria, RS, Brasil. Doutora em Direito. E-mail: angela.espindola@ ufsm.br
Resumo: $\mathrm{O}$ presente trabalho de pesquisa visa analisar o movimento feminista e ecofeminista através do estudo das principais demandas que circundam a Teoria Feminista. Dessa forma, o trabalho verifica que através do engajamento da mulher na Sociedade em Rede, têm surgido formas criativas de lidar com os problemas ambientais e a busca pela igualdade de gênero. Para isso, realizou-se a análise do brechó virtual "Brechados", idealizado por mulheres, o qual possui aspectos significativos para a percepção das teorias de gênero estudadas e da Sustentabilidade, enquanto princípio fundamental no Sistema brasileiro. Para a realização desta pesquisa foram utilizados o método de abordagem dedutivo e método de procedimento Estudo de caso. Os resultados do presente estudo revelam que a essência do Brechó é inspirada pelo movimento feminista e ecofeminista na Sociedade em Rede e prescreve o cumprimento de objetivos com o desenvolvimento sustentável diante da incontestável crise ambiental.

Palavras-chave: Ecofeminismo. Desenvolvimento Sustentável. Sustentabilidade. Sociedade em Rede. Mulheres e meio ambiente.

\begin{abstract}
This research aims to analyze the feminist and ecofeminist movement through the study of the main demands that surround the Gender Theory. Thus, the work verifies that through the engagement of women in the Network Society, creative ways of dealing with environmental problems and the search for gender equality have emerged. For this, we performed the analysis of the virtual thrift store, idealized by women, which has significant aspects for the perception of the studied gender theories and Sustainability,
\end{abstract}

Recebido em: 30.10.2019

Aceito em: 29.06.2020 
as a fundamental principle in the Brazilian System. For this research we used the deductive approach method and the Case Study procedure method. The results of the present study reveal that the essence of Thrift is inspired by the feminist movement in the Network Society and prescribes the fulfillment of goals with sustainable development in the face of the undeniable environmental crisis.

Keywords: Ecofeminism. Sustainable development. Sustainability. Network Society. Women and the environment.

\section{CONSIDERAÇÓES INICIAIS}

O presente estudo objetiva analisar a possibilidade do Brechó Itinerante, virtual, idealizado por mulheres e localizado na cidade de Santa Maria, Rio Grande do Sul (RS), representar alternativas de mudança ao desenvolvimento sustentável. Tais mudanças refletem aspectos da Teoria Feminista, Ecofeminismo, Sustentabilidade e Sociedade em Rede. Diante da grave crise ambiental - que atualmente pode ser compreendida como planetária - não há como eximir-se de analisar as relaçóes destrutivas de comportamento entre si.

$\mathrm{O}$ interesse pelo tema deu-se pelo fato da autonomia e igualdade de gênero, lutas primordiais do movimento feminista, ainda apresentar grandes obstáculos para a sua solidificação no espaço público, apesar de tantos anos de lutas e conquistas de direitos pelas mulheres, representados através das suas grandes pautas e protagonizadas pelo movimento social-político feminista.

Desse modo, no momento em que a mulher é subjugada e colocada numa posição submissa, frente aos ditames do patriarcado, ocorrem as desigualdades de gênero que são criticadas pelo feminismo e Ecofeminismo. No contexto desse trabalho, as duas teorias passam a ser acolhidas e vistas juntas, com o objetivo de recepcionar as suas significaçóes e lançar um debate, sobre a intersecção de raça, classe social, gênero e incluir uma quarta categoria de análise: o meio ambiente.

Dessa forma, o Ecofeminismo, que conta com as mais variadas significações, tem como ideia essencial, a interconexão entre a dominação da natureza pelos seres humanos e a dominação feminina aos homens, revelando a predominância de domínio patriarcal na estrutura social, impulsionados pelo capitalismo, o qual remete o papel da mulher apenas à reprodução e aceitação daquilo que lhe é imposto por homens.

Assim, as relaçóes de poder, em especial as construídas com base no Sistema capitalista e patriarcal, tomam proporções que avançam rumo a desumanização e a destruição do planeta. Embora as legislaçóes dos Estados Democráticos, preponderem pela proteção ambiental, como o Brasil, por exemplo, que possui um Capítulo específico em sua Constituição Federal sobre 
a qualidade ambiental e sua promoção como responsabilidade do Estado e da coletividade, o modo de produção segue centrando-se na exploração da natureza e dos seres humanos.

Em vista disso, têm surgido formas criativas e válidas de lidar com os problemas de gênero e o meio ambiente na sociedade em rede. Tendo em vista que tal indagaçáo demonstrase muito ampla, toma-se por intenção delimitar tal inquietude por intermédio do problema posto a seguir: Frente as problemáticas ambientais e a dominação patriarcal sobre as mulheres, como o Brechó virtual e idealizado por mulheres, pode contribuir para apontar mudanças de desenvolvimento sustentável, que perpassam pela Teoria de gênero, Ecofeminismo, Sociedade em Rede e Sustentabilidade?

Para tanto, vale-se do método de abordagem dedutivo e de procedimento estudo de caso, visto ser necessária a análise do Brechó Itinerante e virtual "Brechados". Como técnicas de pesquisa, adota-se os procedimentos bibliográfico e observação direta. O procedimento bibliográfico tem como propósito a utilização de livros, artigos, legislação nacional e demais referências para o desenvolvimento do tema proposto. Outrossim, o procedimento de observaçáo direta dar-se-á por meio de visita e observação do Brechó "Brechados". A observaçáo direta ocorre com um acompanhamento presencial no espaço supracitado, diagnosticando o dia-a-dia do trabalho, como vendas e aquisição de peças, sujeitando a pesquisadora a um contato mais direto com os aspectos da realidade ora investigada.

Dessa forma, divide-se o trabalho em três importantes desdobramentos.

Num primeiro momento, far-se-á a descrição sobre a Historicidade do movimento feminista, lançando um olhar sobre a história das mulheres, suas expressóes de gênero e os processos de suas próprias lutas que foram protagonizadas pelo movimento feminista até a Sociedade em Rede. Após, apresenta-se a segunda parte deste artigo sobre a influência das tecnologias de informação e comunicação (TIC), através da Sociedade em Rede, analisando o brechó itinerante e virtual sob o viés Ecofeminista. Por fim, analisa-se o desenvolvimento sustentável sob o prisma do princípio da Sustentabilidade incorporado em nossa Constituição.

Com esse propósito, a presente pesquisa é pautada no fundamento ético, que concede aos indivíduos a sua humanidade, a ética dos direitos humanos, que vê o outro como merecedor de igual consideração e respeito, dotado do direito de desenvolver as potencialidades humanas, de forma livre, autônoma e plena. Desse modo, passa-se a analisar a primeira parte desse artigo, que irá da historicidade do movimento feminista, patriarcado e a dominação masculina.

\section{A HISTORICIDADE DO MOVIMENTO FEMINISTA, PATRIARCADO E A DOMINAÇÁO MASCULINA}

Lançar um olhar sobre a história das mulheres pressupóe, indispensavelmente, compreender as suas expressóes, de gênero, de identidade e os processos de suas próprias lutas que foram protagonizadas pelo movimento feminista. Nesse sentido, requer ir além, em seu 
íntimo e perceber a relação natureza/mulher que foi utilizada como uma justificativa biológica para manter relaçóes de poder e opressão de mulheres na sociedade. Assim, a estrutura social acolheu padrōes destrutivos, naturalizando-os.

Portanto, a desigualdade entre homens e mulheres é um traço marcante e presente em todas as sociedades e na maior parte da história não foi camuflada, foi assumida com base na natureza diferenciada do sexo (MIGUEL, BIROLI, 2013). Dessa forma, criaram-se distorçóes sobre o papel social das mulheres, gerando uma suposta naturalização de seus comportamentos que ao longo do tempo, foram associados com a feminilidade e domesticidade.

Logo, não é mais possível discutir sobre a desigualdade na teia social, ignorando a teoria crítica feminista, que parte das questôes de gênero, mas vai além, reorientando os nossos valores e análises, combinando a militância pela igualdade de gênero com a investigaçáo das causas e os mecanismos de reprodução da dominação masculina e o patriarcado. (MIGUEL, BIROLI, 2013, p. 17)

Investigar as causas e os mecanismos da dominação masculina nos remete ao desmoronamento de uma sociedade mais igualitária entre homens e mulheres. Nesse sentido, a historiadora Silvia Federici, em sua obra "Calibã e a Bruxa. Mulheres, corpos e acumulação primitiva" (2017) realizou uma pesquisa sobre o papel das mulheres na transição ocorrida entre o chamado período feudal e o capitalismo, destacando que, em parte da assim dita Idade Média europeia, as mulheres realizavam funçôes tidas (mais tarde) como masculinas e tinham elevado poder social devido ao domínio sobre a atividade reprodutiva de seus corpos e o conhecimento com plantas medicinais.

Também foi nesse período que a Igreja Católica incutiu a ideia de que as mulheres eram perigosas, tinham pacto com o demônio e, portanto, deveriam ser controladas. Dessa forma, o fenômeno da grande "caça às bruxas" (séculos XV-XVII) foi o evento responsável por aniquilar a participação política, a força e a resistência feminina, que até então eram comuns nas sociedades do mundo inteiro. Destaca-se que a maioria das mulheres processadas foram as parteiras, pois até o século XVI, o parto foi considerado um mistério feminino. Foi desprezado o papel que as mulheres tiveram como curandeiras comunitárias e tradicionalmente depositárias de conhecimento e do controle reprodutivo das mulheres na Idade Média (FEDERICI, 2017).

Nesse sentido, com este pano de fundo, "parece plausível que a caça às bruxas tenha sido, uma tentativa de criminalizar o controle de natalidade e de colocar o corpo feminino a serviço do aumento da população e da acumulação da força de trabalho" (FEDERICI, 2017, p. 326). Dessa forma, a sociedade se organizou sob o suporte dos valores patriarcais, os quais foram sendo criados, ensinados, vivenciados e impostos, alterando as relações humanas e identidades masculinas e femininas. Com o passar do tempo, vários setores sociais contribuíram para a implementação e reforço destes valores, que foram intensificados, simbolicamente e juridicamente, na assim dita Idade Média. 
A partir da reorganização das estratégias de relação de poder, as práticas de controle foram aperfeiçoadas e utilizadas para dominar a natureza e os corpos femininos. Ressalta-se que a opressão e dominação da mulher surgiu muito antes do desenvolvimento do capitalismo, mas por ele essas relaçóes foram intensificadas. Desse modo, as mulheres foram estrategicamente encarregadas do trabalho doméstico, considerado gratuito e denominado como trabalho não produtivo, vinculados à natureza da mulher (ANGELIN, 2014).

Desse modo, foi nas câmaras de tortura e nas fogueiras que se forjou os ideais burgueses de mulher na sociedade "surgiu um novo modelo de feminilidade: a mulher e esposa ideal, de poucas palavras e sempre ocupada com as suas tarefas. Esta mudança aconteceu no final do século XVII, depois de séculos de terrorismo de Estado durante a Caça às Bruxas". (FEDERICI, 2017, p. 205)

Devido às ideias iluministas, transformando o século XVIII, no século das luzes e, já preparando o terreno para a Revolução Francesa, o romantismo favoreceu o desenvolvimento e a expressão do amor em todas as suas formas (BAUER, 2001, p. 60). Nota-se a discriminação, consolidada pelo discurso da mulher frágil, emotiva, amorosa, incapaz, portanto, "inferior", não permitindo o acesso ao conhecimento a partir dessa condição opressiva. Assim, (BAUER, 2001, p.60) esclarece:

Com o triunfo da sociedade burguesa introduziu-se um conjunto diferente de tarefas que deveriam ser desenvolvidas pelas mulheres. Com o surgimento das novas ideias apareceram a figura da mãe, do amor materno e da infância. Consolidou-se a ideia da mãe responsável, dedicada a seus filhos, que trouxe profundas repercussóes na vida e na condição da mulher contemporânea. Ao final do século XVIII, as tarefas femininas e masculinas estavam definidas. A mulher burguesa abandonou o trabalho externo e passou a se dedicar prioritariamente ao desempenho das tarefas domésticas, da educação e do cuidado com os filhos. [...] As tarefas desempenhadas pela mulher no âmbito do lar deixaram de ser consideradas trabalho, solapadas pelas ideias do amor, da felicidade familiar e doméstica. [...] De fato, a educação das jovens da nobreza e da burguesia tinha como objetivo principal prepará-las para o casamento, a vida social e o cuidado dos filhos.

Todavia, essa construção que vincula a submissão da mulher na esfera doméstica à sua exclusão da esfera pública contou com a oposição de algumas vozes. Assim, o movimento feminista enquanto movimento político e intelectual surge na virada do século XVIII para o século XIX com o espírito da Revoluçáo Francesa. (MIGUEL, BIROLI, 2003, p. 20)

Nessa esteira, entre as primeiras vozes críticas, destaca-se pela importância e seu significado, a de Olympe de Gouges e Mary Wollstonecraft (BAUER, 2001, p. 61).

Olympe de Gouges, foi uma revolucionária que defendia a igualdade de direitos entre homens e mulheres e em 1791 lançou a "Declaração dos direitos da mulher e cidadâ" como resposta a exclusão das mulheres dos direitos previstos da "Declaração dos direitos do homem e do cidadáo", documento fundamental da Revolução Francesa, tendo sido condena a guilhotina dois anos depois em novembro de 1793 (BAUER, 2001, p. 62). 
Mary Wollstonecraft, em fins do século XVIII, analisava que alguns comportamentos considerados como femininos, aprendidos desde a infância pelas mulheres, eram fruto de ignorância e preconceito. Ela elaborou duras críticas aos filósofos, principalmente a Rousseau sobre a educação em sua obra Reivindicação dos direitos da mulher, assim, é considerada a fundadora do feminismo (BAUER, 2001 e MIGUEL, BIROLI, 2003).

Nesse sentido, "o programa dessa primeira fase do feminismo tinha como eixos a educação das mulheres, o direito ao voto e a igualdade no casamento, em particular o direito das mulheres casadas a dispor de suas propriedades" (MIGUEL, BIROLI, 2003, p. 21). No Brasil, da mesma forma, a primeira fase teve como escopo a luta das mulheres pelos direitos políticos (PINTO, 2003, p. 13).

No entanto, essa primeira fase do feminismo não abarca todas as desigualdades de gênero, raça e classe social. O que se nota é que, em termos globais, as primeiras ondas do feminismo buscavam atender aos interesses próprios de mulheres brancas, que frequentemente (de modo elitista e egoísta) defendiam seus direitos individuais, demonstrando superficialidade e fraqueza ao pautar a questáo da igualdade racial. (DAVIS, 2016. p. 84).

Assim, essa noção de desigualdade de gênero e raça é desenvolvida no final da segunda fase do feminismo, como eloquentemente Sojourner Truth elucidou:

Arei a terra, plantei, enchi os celeiros, e nenhum homem podia se igualar a mim! Não sou eu uma mulher? Eu podia trabalhar tanto e comer tanto quanto um homem- quando eu conseguia comida- e aguentava o chicote da mesma forma! Não sou eu uma mulher? Dei à luz treze crianças e vi a maioria ser vendida como escrava e, quando chorei em meu sofrimento de mãe, ninguém, exceto Jesus, me ouviu! Não sou eu uma mulher? (DAVIS, 2016, p. 71).

Esse discurso, ainda no século XIX, já evidencia um grande dilema que o feminismo hegemônico viria a enfrentar: a universalização da categoria mulher. "Esse debate de se perceber as várias possibilidades de ser mulher, ou seja, do feminismo abdicar da estrutura universal ao se falar de mulheres e levar em conta as outras intersecçôes" (RIBEIRO, 2017, p. 23).

Na passagem do século XIX para o século XX um olhar mais plural de feminismo se estabeleceu. Em geral, o direito ao voto foi obtido pelas mulheres nas primeiras décadas do século, bem como as barreiras do acesso à educação foram levantadas, com o acesso das mulheres a todos os níveis de ensino. Destaca-se que lentamente os códigos civis passaram a afirmar a igualdade de direitos entre os cônjuges (MIGUEL, BIROLI, 2003, p. 24).

Com esse cenário, a figura de Simone de Beauvoir, surge como um dos nomes do feminismo contemporâneo, com a publicaçáo de O segundo sexo, em 1949, com uma tentativa de entender a construçâo social do "feminino" como um conjunto de determinaçôes e expectativas destinado a cercear a capacidade da mulher (MIGUEL, BIROLI, 2003, p. 25). Assim, fundamento deste entendimento, afirma que:

Ninguém nasce mulher: torna-se mulher. Nenhum destino biológico, psíquico, econômico, define a forma que a fêmea humana assume o seio da sociedade; é o conjunto 
da civilização que elabora esse produto intermediário entre o macho e o castrado, que qualificam de feminino. (BEAUVOIR, 1967, p.9)

Nesta segunda onda do feminismo, inaugura por Simone de Beauvoir, em 1949, se inicia a discussão entre o sexo e gênero, em que o sexo passa a ser entendido como uma característica biológica, e gênero, como construção social, um conjunto de papéis impostos à pessoa a depender do seu sexo. Do mesmo modo, se abriu caminho para uma discussão a respeito de uma epistemologia feminista distinta da epistemologia dominante, masculina (MIGUEL, BIROLI, 2003, p.26).

Nota-se, pois, que a citada obra de Simone de Beauvoir é um marco da segunda onda do feminismo, abrindo caminho para questionar a dicotomia entre o público e o privado, a objetificação da mulher e, sobretudo questionar a construção social de gênero. Essa fase, é essencial, para entender que a divisão social existente entre homem e mulher, forte e fraco, ríspido e sensível, nada mais é do que uma construção da modernidade que serviu como importante sustentação à ordem patriarcal mundial, que predominava no processo social de distinção entre sexos.

No brasil, salienta-se, que com o acesso aos Direitos políticos em 1932, as mulheres permaneceram na condição de incapazes, fato que só foi modificado com o Estatuto da Mulher casada, Lei no 4.121, de 17 de agosto de 1962, apenas amenizando as discriminaçóes de gênero, ainda, com muitas limitaçóes de acesso igualitário nas relaçóes conjugais e à esfera pública, diante da relação de poder estabelecida com o casamento, conforme as concepções da época (PINTO, 2013, p.25-55). Nesse sentido, a tese de inferioridade feminina defendida pelos legisladores masculinos, originava-se a partir do discurso de mulher frágil, emotiva e, portanto, com capacidade mental reduzida, diante da tradicional visão da sua natureza fraca.

Nessa perspectiva, evidencia-se a importância do movimento feminista, eis que coloca como central a importância da problemática da dominação entre os sexos e as suas consequências. Assim, esclarece (Apfelbaum, 2009, p.76) sobre o conceito de dominação:

Toda relação de dominação, entre dois grupos ou duas classes de indivíduos, impóe limites, sujeição e servidão àquele(a) que se submete. Ela introduz uma dissimetria estrutural que é, simultaneamente, o efeito e o alicerce da dominação: um se apresenta como representante da totalidade e o único depositário de valores e normas sociais impostas como universais porque os do outro são explicitamente designados como particulares. Em nome da particularidade do outro, o grupo dominante exerce sobre ele um controle constante, reivindica seus direitos fixando os limites dos direitos do outro e o mantém num estatuto que retira todo o seu poder contratual. A dissimetria constituinte da relação de dominação aparece não somente nas práticas sociais, mas também no campo da consciência e até nas estratégias de identidade.

Verifica-se que a dominação é quase um sinônimo do patriarcado, pois não representa somente o poder dos homens individualmente sobre as mulheres, mas por uma ordem social, além disso, entre as características em comum, apresentam que a subordinação das mulheres é 
também uma das consequências do capitalismo. (SAFFIOTI, 2002). Em concordância com essas constatações, tem-se os ensinamentos de Delphy, 2009, acerca do conceito de patriarcado:

[...] patriarcado designa uma formação social em que os homens detêm o poder, ou ainda, mais simplesmente, o poder é dos homens. Ele é, assim, quase sinônimo de "dominação masculina” ou de opressão das mulheres. Essas expressóes, contemporâneas dos anos 70, referem-se ao mesmo objeto, designado na época precedente pelas expressôes "subordinação" ou "sujeição" das mulheres, ou ainda "condição feminina". [...] "Patriarcado" vem da combinação das palavras gregas pater (pai) e arkhe (origem e comando). (p. 173-174)

A terceira fase do movimento de mulheres, inicia com os questionamentos propostos pela segunda fase, no entanto, indagando a construção de mulher "universal"- reivindicando condiçóes mais especificas para abarcar outras condiçóes de dominação e opressão, como classe social, raça, sexualidade, além do gênero. "Visôes renomadas dessa posição apareceram no feminismo latino-americano do século XXI, na busca de uma perspectiva que unisse o pensamento decolonial com as questóes de gênero, privilegiando as mulheres do hemisfério sul" (MIGUEL, BIROLI, 2003, p. 26).

Assim, a época dos anos 80 para os anos 90 do século XX foi marcada por eventos históricos importantes, que trouxeram mudanças para o mundo ocidental, "tais como a queda do muro de Berlim (1991), também se dissolviam as ditaduras militares na América Latina como a Argentina, em 1981, a do Brasil, em 1985, a do Chile, 1990” (SILVA, 2019, p. 5).

Nesse sentido, nota-se a representação e condição singular da mulher na América Latina, tanto no que se refere ao histórico de exploração e colonização, como na ocorrência recente de governos ditatoriais, o que confere ao povo latino-americano, especialmente às mulheres, uma situaçáo peculiar com relação a conquista de direitos e desigualdades sociais profundas em relação aos povos do Norte. Nesse ponto, Ribeiro, 2017, corrobora:

[...] A pensadora feminista negra Lélia Gonzalez refletiu sobre a ausência de mulheres negras e indígenas no feminismo hegemônico. [...] reconhecia a importância do feminismo como prática no combate às desigualdades, no enfrentamento ao capitalismo patriarcal e desenvolvendo buscas de novas formas de ser mulher. [...] para a autora faltava incluir outro tipo de discriminação tão grave quanto as outras citadas: a opressão de caráter racial. (p. 27)

A terceira onda, portanto, buscou o reconhecimento das várias identidades e diferentes experiências das mulheres. Foi a partir desse momento, que a ideia de interseccionalidade ganhou força dentro do feminismo. Assim, as lutas feministas produziram avanços teóricos e práticos, na legislação relativa à violência doméstica, ao estupro em diversas partes do mundo, mas permanece alto o número de estupros e de assassinatos de mulheres por homens com quem tiveram relações afetivas, justamente pelo fato de que, ainda permanece a visão patriarcal, da mulher como sendo um mero objeto de dominação.

Com esse cenário, na sociedade em rede, o Feminismo é caracterizada pelo uso maciço da Internet com o fim de organização, articulação e denúncias de assédio e, principalmente 
propagação da ideia de que a igualdade ainda é uma ilusão diante dos altos índices de assassinatos e discriminaçóes de gênero (SILVA, 2019, p. 8). Portanto:

[...] a Quarta Onda surgiu pelo avanço das tecnologias de informação e comunicaçáo (TIC), usadas para contestar a misoginia, sexismo, LBTfobia e outros tipos de desigualdade de gênero. $O$ feminismo se apropriou com força do ambiente virtual, de maneira que a internet foi fundamental para isso. A popularização da internet tem influência crucial no despertar do novo feminismo. [...] a expressão "Ni Una Menos" tomou as marchas é um exemplo disso. O marcador surgiu na Argentina, quando uma adolescente de 14 anos foi assassinada pelo namorado de 16 anos, ela estava grávida e foi enterrada no quintal da casa dos avós dele com a ajuda dos pais. Ele a esganou e, depois de matá-la, enterrou o corpo. (SILVA, 2019, p. 8)

Nesse sentido, através da articulação na internet, mulheres se unem para denunciar as violências sofridas. Surgem campanhas com o intuito de encorajar mulheres a denunciar as violências do cotidiano. Assim, também questionam a representação da mulher nos canais de comunicação, questionando os padróes de beleza impostos pela sociedade. "Nota-se, pois, que as questóes da quarta onda são a "liberdade" e os "respeito às diversidades" e a preservação do nosso planeta (SILVA, 2019, p. 13 e CONNELLI; PEARSE, 2015, p. 220). Na concepção de Lévy (1999, p. 11) a Internet está longe de resolver todos os problemas sociais e culturais existentes, porém, o autor reconhece:

Que o crescimento do ciberespaço resulta em um movimento internacional de jovens ávidos para experimentar, coletivamente, formas de comunicação diferentes daquelas que a mídia clássica nos propóe. Em segundo lugar, que estamos vivendo a abertura de um novo espaço de comunicação, e cabe apenas a nós explorar as potencialidades mais positivas deste espaço nos planos econômico, político, cultural e humano. (LEVY, 1999, p. 11)

Tal constatação, demonstra o quanto as ondas se cruzam e organizam-se como forma de reivindicar direitos em contextos específicos de opressão e dominaçáo, trazendo, por exemplo, pautas mais globais e plurais sobre uma conexão comum com a natureza e o movimento de mulheres no feminismo atual, diante da intensidade dos problemas ambientais e o patriarcado como sistema social.

Nota-se que a visão predominante da sociedade capitalista patriarcal é de que as mulheres estão intrinsicamente ligadas à natureza, motivo esse suficiente para naturalizar seus papéis e oprimi-las. Por esse motivo, a questáo central desse debate gira em torno do fato de que, assim como as mulheres, na visão capitalista e patriarcal, a natureza não passa de um mero objeto de exploração. (ANGELIN, 2014).

Assim, no novo milênio é cada vez mais necessário compreender o gênero como parte das mudanças ambientais, a libertação das mulheres e a preservação do nosso planeta. Corroborando com isso, ARRUTA; BHATTACHARYA e FRASER, 2019, ensinam que:

No Sul Global, elas constituem a vasta maioria da força de trabalho rural, ao mesmo tempo carregam a responsabilidade pela maior parte do trabalho de reprodução social. Devido ao seu papel central em prover alimentação, vestimenta e abrigo para a família, 
as mulheres representam parcela descomunal no trabalho de lidar com a seca, a poluiçáo e a superexploração da terra. [...] As mulheres também estão na linha de frente das lutas contra a catástrofe ecológica e moldam formas novas e integradas de luta. (p. 84)

Assim, a teoria de gênero sobre o meio ambiente não é apenas realizar críticas, mas também construir formas de conhecimento que possam revisar e deslocar as formas para uma mudança, transcendendo a identificação política com a Mãe-Terra e subverter as ideias dos movimentos de mulheres sobre o retorno a uma unidade original com a natureza, esse é um desafio para teoria social em geral (CONNELLI; PEARSE, 2015).

Nesse sentido, diante da influência das TIC $^{1}$ no movimento feminista, têm surgido formas criativas de lidar, tanto com os problemas ambientais, quanto buscar a igualdade de gênero. Esse ponto, será abordado no próximo capítulo deste estudo.

\section{ECOFEMINISMO E SOCIEDADE EM REDE: ALIANDO ECOLOGIA AO FEMINISMO PARA MUDANÇAS SUSTENTÁVEIS}

Com o advento da nova rede de comunicação global: a internet, a natureza de cidadania democrática passa por uma profunda evolução, que se encaminha no sentido de um aprofundamento da liberdade. Além disso, com o desenvolvimento de uma consciência sobre a crise ecológica em que vivemos com a implantaçáo do consumo socialmente responsável, utilizam-se novas possibilidades de escolha de consumo, o que estabelece, que certas finalidades éticas, sociais ou políticas transformem-se em liberdade política (LEVY, 2002, p. 30).

Assim, em certo sentido, "toda a teoria feminista é política, na medida em que é fundante, no feminismo, a compreensão de que os limites convencionais da política são insuficientes para apreender a sua dinâmica real, da categoria gênero" (MIGUEL, BIROLI, 2003, p.7).

Por isso, a teoria feminista é tão singular nessa luta, por justiça ambiental, por igualdade de gênero e pela desconstruçáo da cultura patriarcal, pois o ponto de partida em comum dos diversos movimentos feministas, é reconhecer que os danos ao meio ambiente impactam mais seriamente os pobres, negros, mulheres, indígenas e outras minorias (CONNELLI; PEARSE, 2015).

Nesse sentido, "a expansão da Internet é suportada por lugar de cuja força não se tem conseguido medir a amplitude”. Assim, são os próprios agentes, as pessoas e os movimentos que decidem o que querem publicar na rede (LEVY, 2002, p.56). Por isso, o feminismo, que vivemos, emerge na era digital da Sociedade em Rede, e está diretamente ligada às demandas das pessoas das regióes periféricas do ocidente, aquelas que não tiveram espaço para serem ouvidas, e com a internet encontraram esse espaço, como é o caso dos países da América Latina (SILVA, 2019, p. 15).

1 As TIC podem ser definidas como um "conjunto de dispositivos, serviços e conhecimentos relacionados a uma determinada infraestrutura, composta por computadores, softwares, sistemas de rede” (VELOSO, 2011, p. 49), que conseguem efetuar a produção e distribuição de informaçóes aos novos atores sociais. 
Segundo Levy (2002, p.57), o resultado disso é o desabrochar da diversidade, assim como a liberdade que atinge quem explora as redes com seriedade. As pessoas têm muitas coisas a dizer, imagens e músicas a difundir, têm injustiças a denunciar, sofrimentos a expressar. Este soltar a palavra é uma forma de poder dizer e finalmente ser ouvido. Com relação a isso, de acordo com Silva (2019, p.15), a popularização da internet, tem um papel crucial na formação desse novo feminismo, porque deu voz a outros grupos, que o movimento tradicional ainda não tinha conseguido abarcar.

Diante do cenário apresentado, esse trabalho propóe despir-se de certas limitaçóes bibliográficas sobre o tema, e por meio da análise do Brechó virtual "Brechados", idealizado por mulheres, realizou-se um estudo de caso, conhecendo as práticas de organização de conteúdo manifestado através da internet e como são estabelecidas as condutas de venda e aquisição das peças do Brechó.

A loja "Brechados" fica localizada no centro da cidade de Santa Maria-RS, e conta com o auxílio da internet, que através das redes sociais, consegue mostrar as suas peças, atrair clientes, realizar vendas e também compras, já que a maioria de suas peças, é oriunda de fornecedores que são amigos ou clientes que enviam fotos através de suas redes. Assim, após o garimpo por meio virtual, vem a seleção das roupas, trabalho esse, realizado pelas donas da loja.

O Brechó nasceu em 2017, a partir do espírito empreendedor de duas mulheres, que buscavam trazer algo novo, assim refletiram sobre o (Re)uso de peças de roupas de maneira Itinerante, levando suas araras com peças de roupas em feiras e eventos da cidade. Com a demanda e procura muito grande montaram a loja "Brechados", o nome é a associação de Brechó com Achados, o que é exatamente o objetivo da loja, trazer um conceito novo, demonstrando que o Brechó não é algo velho e em mal estado, retirando o preconceito geral da sociedade.

As postagens das peças de roupas ocorrem sempre nas quartas-feiras, através das redes e, a importância da ferramenta é tão grande para o Brechó, que se não ocorrem os posts, o público não comparece à loja, bem como o alcance que acaba sendo muito maior, uma vez que conseguem atingir pessoas de outros Estados do Brasil. Nesse sentido, (VOLKMER et al., 2011, p.10) ressaltam:

é impressionante a velocidade em que tudo acontece na rede. Uma rede de relacionamento pode ser construída em poucos minutos, e com ela o usuário pode estabelecer relaçôes com o mundo inteiro. Nas chamadas redes sociais, verifica-se uma interação inédita entre os indivíduos. Elas permitem aproximação, compartilhamento de conteúdo e troca inesgotável de informaçóes. Em um segundo, é possível estar conectado com pessoas que se encontram em coordenadas geográficas diametralmente opostas [...]. Esse certamente é outro legado fundamental da nova cultural digital: a facilidade de formarse consciência política.

Destaca-se, que diante das mudanças sociais tão expressivas quanto os processos de transformação tecnológica e econômica a consciência ambiental permeou as instituiçóes da 
sociedade e seus valores ganharam apelo político na sociedade em rede (CASTELLS, 1999, p.22). De outro modo, Manuel Castells (2015, p. 70) esclarece que uma Sociedade em Rede é: [...] uma sociedade cuja estrutura social é construída entorno de redes ativas por tecnologias de informação e comunicação processadas digitalmente e baseadas na microeletrônica. Considero estruturas sociais como arranjos organizacionais de seres humanos em relaçóes de produção, consumo, reprodução, experiência e poder, expressos em uma comunicação significativa codificada pela cultura.

Nessa senda, as novas tecnologias da informação e comunicação (TIC) impulsionaram a atual conjuntura, em que fronteiras geográficas foram extinguidas, as distâncias comunicacionais diminuíram e a sociedade foi reunida mediante o fluxo informacional e comunicacional intenso, que reduziu as diferenças no espaço da rede mundial de computadores (BAUMANN, 1999, p. 24).

O que se compreende, através do estudo, é que a essência do Brechó é inspirada pelo Feminismo e Ecofeminismo na sociedade em rede, que é influenciada pelas (TIC) "que agem como instrumentos inovadores no aceleramento da comunicaçáo, estimulam a interatividade, modificam a produção e transformam as relações entre os indivíduos" (VELOSO, 2011, p. 50).

Assim, por intermédio da experiência prática, buscam uma transformação na mentalidade e no comportamento social para promover uma construção de consciência ecológica e com o empreendedorismo feminino, que chega a ser profunda, pelo engajamento e comprometimento, concentrada não só nos interesses próprios, mas de outras mulheres trabalhadoras, para propagar o propósito do Brechó e do (Re)uso de peças de roupas, acessórios e calçados, através de eventos, feiras na cidade e parcerias na própria loja, mobilizando através da rede e, assim valorizando o trabalho e empoderamento de outras obreiras. Na concepção de Bernardes (2013, p. 23):

O século XXI, assistiu-se a uma (re)configuração da cidadania [...]. O caso acima reforça os aspectos positivos da Sociedade Informacional, dentre os quais vale destacar a visibilidade das minorias que passam a ter voz e vez, e a potencialidade dos trabalhos cooperativos, pois na estrutura da Internet, a emissão só faz sentido se o conteúdo estiver conectado a outros.

Tal constatação nos leva a inquirir sobre como o gênero atua sobre as respostas existentes a crise e na sociedade. Desse modo, que mudanças de gênero serão necessárias para fazermos uma transição para uma sociedade ecologicamente sustentável? Existe alguma relação entre a exploração da natureza diante das dominaçôes das mulheres nas relaçôes de gênero?

Essas e outras questôes têm sido debatidas por escritoras feministas e ecofeministas desde 1970 e potencializadas na Sociedade em Rede. Nesse sentido, o ecofeminismo surge como uma fonte de pensamento que abarca a luta de mulheres por direitos iguais, contrapostos às opressóes de gênero produzidas num sistema patriarcal. O termo surgiu nos anos setenta, na França, pela escritora Françoise d'Eaubonne, a partir das inquietaçóes com o largo crescimento demográfico, com a degradação do meio ambiente e com a dominação masculina sofrida pelas mulheres (CONNELLI; PEARSE, 2015). 
Assim, as ecologias críticas conduzem à ideia de que existe um conjunto de tendências que "superam a simples contraposição entre antropocentrismo, biocentrismo e ecocentrismo defendendo posiçóes críticas muito mais radicais, porque analisam questôes de fundo que não são levadas em consideração pelas tendências anteriores" (JUNGES, 2010, p. 31-32). Nesse sentido, é das ecologias profundas que surge o ecofeminismo, escola que tem direcionado movimentos feministas e ambientalistas.

Desse modo, a natureza precisa ser incorporada como uma quarta categoria de análise da teoria feminista, que lida com raça, gênero e classe social (CONNELLI; PEARSE, 2015). Os movimentos sociais, especialmente o feminista, têm questionado sobre o elemento de classe social e as identidades, sobre isso (SILVA, 2009, p.36) ensinam que:

Essa concepçáo baseia-se na análise que Marx fez da relação entre base e superestrutura, na qual as relaçôes sociais são vistas como determinadas pela base material da sociedade, argumentando, assim, que as posiçóes de gênero podem ser "deduzidas" das posiçóes de classe social. Embora essa analise tenha apelo de uma relativa simplicidade e da ênfase na importância dos fatores econômicos materiais como determinantes centrais das posiçóes sociais, as mudanças sociais recentes colocam essa visão em questão. [...] As identidades baseadas na "raça", no gênero, na sexualidade e na incapacidade física, por exemplo, atravessam o pertencimento de classe. $\mathrm{O}$ reconhecimento da complexidade das divisões sociais pela política de identidade, na qual raça, a etnia e o gênero são centrais, tem chamado a atenção para outras divisôes sociais, sugerindo que as formas como são representadas têm pouco impacto sobre sua definição.

Assim, as formas pelas quais a cultura estabelece fronteiras e distingue diferenças são cruciais para entender as identidades na contemporaneidade, frequentemente por meio de uma oposição entre "nós e eles", por exemplo. (SILVA, 2009, p.41) O que ocorre, é que a cultura ocidental produziu uma separação da natureza e da humanidade. Nesse caso, as oposiçôes são o mecanismo central de dominação do outro (CONNELLI; PEARSE, 2015, p.237). Assim, é por meio dessas dicotomias que o pensamento, especialmente o pensamento europeu, tem garantido a permanência de relaçôes de poder existentes (SILVA, 2009, p.53).

Nesse seguimento, salienta-se a importância desta iniciativa de trabalho do "Brechados" no dado momento em vivemos, no qual as mudanças nos processos sistemáticos da Terra já excedem níveis nos quais o planeta poderia se manter equilibrado e para que a humanidade exista.

"A humanidade como um todo está ameaçada, embora haja riscos muito maiores às pessoas pobres do Sul Global com as mudanças climáticas. Assim, podemos dizer que a mudança ambiental é uma crise para toda a humanidade, mas seus impactos são altamente desiguais" (CONNELli; PEARSE, 2015, p.222-223). Desse modo, (Crutzen; Stoermer, 2000 apud Connelli; Pearse, 2015, p. 222) ensinam:

Cientistas da natureza nos informam que os limites planetários foram ultrapassados em pelo menos três aspectos: mudanças climáticas ligadas ao aumento de fases de efeito estufa na atmosfera; perda da biodiversidade e extinção de espécies; interrupção do ciclo do nitrogênio por intermédio da agricultura moderna. [...] O químico da atmosfera e 
ganhador do prêmio Nobel Paul Crutzen e seus colegas defenderam que um novo nome é necessário para esta geológica. Com o termo "Antropoceno", eles destacaram o papel dos seres humanos na propulsão dessas transformaçōes. (Grifo nosso)

Nessa seara, interpretaçóes sobre o que esta nova era significa para a sociedade são alarmantes e desafiam a compreensão sobre o que é o ser humano, frente aos conflitos e instabilidades sociais sombrias e impactos altamente generificados.

À vista disso, manter-se alerta sobre às causas sociais da crise ecológica também suscita questôes de gênero. "Mesmo o termo "Antropoceno" chama a atenção. Em grego, anthropos se refere a um ser humano macho, apesar de também ser usada para todos os humanos, como o termo "homem" [mankind]" (CONNELLI; PEARSE, 2015, p. 223).

A Ecofeminista Vandana Shiva (1998) afirma que a religiosidade vem a ser um fator importante para a construção de um meio ambiente eticamente sustentável, pois mobiliza as pessoas e trabalha com princípios mais voltados para a ética da responsabilidade. Conforme destaca, a Shiva (1998, p. 95) a recuperação do princípio feminino é uma resposta às múltiplas dominaçóes e privaçóes sofridas não só pelas mulheres, mas também pela natureza e pelas culturas não ocidentais. Eles representam a recuperação econômica e a libertação da natureza, a libertação de mulheres e a libertação de homens que, dominando a natureza e as mulheres, sacrificaram sua própria humanidade. Assim, para a autora, a recuperação do princípio feminino baseia-se na amplitude e consiste em:

recuperar na Natureza, a mulher, o homem e as formas criativas de ser e perceber. No que se refere à Natureza, supóe vê-la como um organismo vivo. Com relação à mulher, supóe considera-la produtiva e ativa. E no que diz respeito ao homem, a recuperação do princípio feminino implica situar de novo a ação e a atividade em função de criar sociedades que promovam a vida e não a reduzam ou a ameacem (SHIVA, 1998, p. 96)

Nesse sentido, o ecofeminismo, em síntese, busca explicar a relação entre a dominação da natureza e a dominação da mulher pelo sistema patriarcal. Para Junges (2010, p. 33), o ecofeminismo destaca "o caráter e o significado das relaçôes entre o modo de tratar a mulher e a natureza”. Dessa forma, existe uma dependência específica entre a sociedade patriarcal e a subjugação da natureza.

O ecofeminismo poderia ser analisado como uma escola especial de ecologia social, tendo em vista que ela também discute o processo de dominação social em meio ao contexto do patriarcado. Assim, as teorias ecofeministas analisam "a dominação patriarcal de mulheres por homens como o protótipo de todas as formas de dominação e exploração: hierárquica, militarista, capitalista e industrialista" (CAPRA, 1996, p. 17-18).

Conforme destaca, novamente, Junges (2010, p. 33), os danos ao meio ambiente natural são um resultado lógico "do modo de se relacionar com a natureza presente no paradigma cultural do patriarcado”. Para este autor, deve haver ligação entre a construção de uma ética ambiental que leve em consideração essas relações de dominação sobre a mulher e a natureza. Da mesma 
forma, o ecofeminismo tem como enfoque analisar o androcentrismo, bem como denuncia a ligação fálica, presente na própria linguagem, que subsiste com a natureza, como por exemplo, quando se menciona que as florestas virgens devem ser desbravadas (JUNGES, 2010, p. 33).

O ecofeminismo, então, pode ser verificado através de alguns princípios gerais, os quais são analisados por Siliprandi (2000, p. 63):

a) Do ponto de vista econômico, existe uma convergência entre a forma como o pensamento ocidental hegemônico vê as mulheres e a Natureza, ou seja, a dominação das mulheres e a exploração da Natureza são dois lados da mesma moeda da utilização de "recursos naturais" sem custos, a serviço da acomulação de capital; b) Para o ecofeminismo, o pensamento ocidental identifica, do ponto de vista político, a mulher com a Natureza e o homem com a cultura, sendo a cultura (no pensamento ocidental) superior à Natureza; a cultura é uma forma de "dominar" a Natureza; daí decorre a visão (do ecofeminismo) de que as mulheres teriam especial interesse em acabar com a dominação da Natureza, porque a sociedade sem exploração da Natureza seria uma condição para a libertação da mulher; c) As políticas científicas e tecnológicas que têm orientado o desenvolvimento econômico moderno são políticas que reforçam essa visão, não sendo "neutras" do ponto de vista de gênero ou ambientais. A própria forma de pesquisar a história tem seguido esses princípios, e portanto não tem evidenciado como se deu a exclusão das mulheres do mundo do conhecimento "científico" e como a sua visão de mundo (de integraçáo com a Natureza) foi sendo subjugada pela ideia de dominação.

$\mathrm{Na}$ sociedade patriarcal, homens não são apenas favorecidos por serem homens, mas também porque eles detêm poder político e econômico superior ao das mulheres. A mudança para um sistema de valores mais igualitários se torna táo difícil por essa razão, tendo em vista que, o poder, como dominaçáo sobre o outro, é proveniente de uma autoafirmação excessiva (CAPRA, 1996, p. 19). Assim, a estrutura social é organizada pela hierarquia, onde os homens ocupam posiçóes superiores com mais frequência.

Os estudos feministas sobre problemas ambientais mostram que o gênero é inexoravelmente parte da mudança ambiental. Assim, a preocupação do ecofeminismo com o mau desenvolvimento, colonialismo e imperialismo na geração de problemas ambientais, em âmbitos local e global no novo milênio, é cada vez mais necessário para a reforma de gênero democráticas em outras esferas na teia social. (CONNELLI; PEARSE, 2015)

Desse modo, relaçôes de gênero democratizadas contribuirão para reformas sustentáveis de organização social e política, consequentemente um papel significativo na construção de um mundo mais democrático o que significa: caminhar em direção à igualdade de participação, de poder, de recursos e, sobretudo de respeito a diversidade cultural e social, pauta táo defendida nas plataformas de redes sociais, através da Internet, pelas feministas e militantes engajadas com as causas do movimento social.

Assim, representará não só um avanço do movimento de mulheres, mas também do próprio Ecofeminismo, uma vez que, os sistemas ecológicos e geológicos da Terra estão mudando para um clima muito mais instável, resultado do desmatamento de terras, queima de 
combustíveis fósseis, consumo de animais em proporção insustentável, contaminação do solo e da água através da indústria, entre outros fatores, em que o modo de exploração capitalista centra-se na exploração da natureza e dos seres humanos, contribuindo para o aprofundamento das crises ambientais e desenvolvimento humano.

\section{O DESENVOLVIMENTO SUSTENTÁVEL E O PRINCÍPIO DA SUSTENTABILIDADE}

A problemática ambiental há muito tempo tornou-se o centro de discussões jurídicas e políticas no cenário mundial. No entanto, a evolução tecnológica permite um maior alcance e conscientização sobre os reflexos que a degradação ambiental causará as presentes e gerações futuras. Assim, a humanidade encontra-se em um momento muito delicado e repleto de crises sistêmicas que interagem entre si.

Desse modo, tanto a solução para a crise ambiental, quanto a opressão das mulheres não deve ser tratada como problemas isolados. Juarez Freitas ensina que "para avançar a bandeira da sustentabilidade, vários muros mentais terão de cair” (2016, p.26).

Nesse sentido, a sociedade do conhecimento terá de se tornar sociedade do autoconhecimento, voltada para o crescimento do bem-estar universalizado (FREITAS, 2016, p. 29). Por esse motivo, a Sustentabilidade deve ser considerada prova viva da emergência de racionalidade dialógica, interdisciplinar, criativa e antecipatória (FREITAS, 2016, p.31). O que refere-se proteger e preservar a natureza e seus recursos em sentido Lato.

A sustentabilidade encontra nesse modelo seu grande desafio, para além de uma mudança conceitual, interpretativa, mais profundamente exige para sua verdadeira compreensão uma mudança "mental" da sociedade. (FREITAS, 2016, p.25). Do mesmo modo, ensina que:

[...] há uma verdade inevitável no caminho da sustentabilidade: "o vício mental do crescimento pelo crescimento, a qualquer custo, não será vencido sem as dores da síndrome da abstinência. A sociedade terá, em dado momento, de querer se desintoxicar de prévias compreensóes desastrosas e redesenhar o sistema em que vive". (FREITAS, 2016, p.26)

Desse modo, a sustentabilidade não deve ser entendida apenas como um conceito vazio, ou mera ferramenta de propaganda ou falsa reputação a ser utilizado e não aplicado. Muito além de mero interesse econômico, de mercado e crescimento, as grandes questóes ambientais devem ser entendidas como naturais, sociais e econômicas simultaneamente. (FREITAS, 2016, p.31)

Há quem diga que não existe e nunca vai existir “desenvolvimento sustentável”, contudo, é possível verificar que o desenvolvimento não precisa ser contraditório à sustentabilidade. Quando reconcebido e desatrelado do modelo instituído e enraizado na sociedade, o desenvolvimento pode e deve ser sustentável, contínuo e duradouro (FREITAS, 2016, p.42).

A superação do modelo instituído de desenvolvimento na sociedade atual que nada tem a ver com o sustentável, realça a necessidade da concepção dos termos a partir de uma característica 
multidimensional indissolúvel, que considere as dimensóes social, ambiental e econômica, mas também inclua a dimensão jurídico-política, uma vez que trata-se de princípio constitucional gerador de novas obrigações assim como sua dimensão ética (FREITAS, 2016, p.24).

Esse novo paradigma da "sustentabilidade", ressalta a importância da consideração de suas diversas dimensões que são interdependentes e indivisíveis quando atreladas ao termo em questáo. Segundo Freitas (2016) alguns aspectos nucleares devem estar reunidos para que este paradigma possa se implementar na sociedade, dentre eles:

a consideração de que sustentabilidade é uma determinação ética e jurídico institucional, constitucionalmente tutelado no Brasil no art. 3․, 170, VI, e 225; é uma determinaçáo ética e jurídico-institucional de responsabilização objetiva do Estado pela prevenção e precaução; é uma determinação ética e jurídico-institucional de sindicabilidade ampliada de escolhas públicas e privadas; é uma determinação ética e jurídico-institucional de responsabilidade pelo desenvolvimento de baixo carbono, compatível com os valores constitucionais que não se coadunam com a ânsia mórbida do crescimento econômico como fim em si. (p. 32)

A partir dessa construção, verifica-se que é a sustentabilidade que deve nortear o desenvolvimento e não o contrário. A partir de uma releitura, uma reconstrução valorativa e "esverdeada" de todo ordenamento jurídico, estando a sustentabilidade em todas suas dimensóes norteadoras de aplicação constitucional.

Nesse sentido, tem-se a proposta do autor Juarez Freitas em instituir um conceito de Sustentabilidade a partir de novo paradigma proposto como princípio constitucional no sentido de que "[...] que determina com eficácia direta e imediata, a responsabilidade do Estado e da sociedade pela concretização solidária do desenvolvimento socialmente inclusivo e equânime, ambientalmente limpo, ético e eficiente, no intuito de assegurar, no presente e no futuro, o direito ao bem-estar" (FREITAS, 2016, p. 41).

Este conceito para ser operacionalizado, reúne alguns elementos indispensáveis que devem ser considerados para transformar o cenário de degradaçáo, dominaçáo, exploração e desenvolvimento predatório do qual faz-se parte. Entretanto, implica uma reformulação do sistema judiciário desde suas bases de desenvolvimento e legislação até o âmbito mais subjetivo de influência. Esse é um desafio para os Juristas e para a sociedade, o qual dependerá uma reconstrução objetiva à luz da Sustentabilidade.

Cabe destacar que o pensamento humano se estrutura em torno do dualismo racional/ irracional, pensamento/sentimento, público/privado, universal/particular, o dualismo acaba sendo um mecanismo central para dominação com um todo.

Nessa perspectiva, a ciência do Direito se coloca no lado masculino destes pares, ou seja, o direito está identificado com a razáo, com padróes objetivos e universais e, o feminino, constitui-se da emoçáo e da subjetividade, do concreto e privado (OLSEN, 1990, p.3). Assim, para a autora: 
As práticas sociais, políticas e intelectuais que constituem o direito foram, durante muitos anos, levadas a cabo quase exclusivamente por homens. Dado que as mulheres foram por longo tempo excluídas das práticas jurídicas, não surpreende que os traços associados com as mulheres não sejam muito valorados no direito. Por outra parte - em uma espécie de círculo vicioso -, se considera que o direito é racional e objetivo, entre outras coisas, por que é valorado e, a sua vez, tão valorado porque se considera racional e objetivo. (OLSEN, 1990, p.4).

Assim, estratégias feministas para atacar este sistema devem ser construídas a partir da luta por identificar as mulheres também como lado racional e ativo, rechaçar a hierarquia estabelecida entre os pares duais, questionando as diferenças. Desse modo, devem ser deslocadas as formas socialmente convencionadas, para trazer mudanças significativas, inteligentes e criativas como o "Brechados", recuperando o princípio feminino de ser e perceber a natureza e as mulheres, e que sejam construídas através de pontes de diálogo, capazes de interligar o respeito e solidariedade à luz da Sustentabilidade. Acima de tudo, é necessário que a humanidade tenha presente a ética do cuidado com todos os seres humanos e a biodiversidade do planeta, preservar é uma tarefa de todas e todos, assim como dos governos.

\section{CONSIDERAÇÓES FINAIS}

Através do estudo, buscou-se analisar as principais pautas do movimento de mulheres até o feminismo na contemporaneidade que é caracterizado pela articulação na internet. De início, compreendeu-se que as pautas iniciais do feminismo não conseguiam abarcar todas as desigualdades e pluralidades de mulheres, essa foi a principal característica da primeira onda. Preliminarmente, portanto, as especificidades coletivas de mulheres negras e indígenas não eram abarcadas pelo movimento, que ainda desconsiderava a condição de cidadãs desses grupos étnicos.

Isso posto, com a passagem do século XIX para o século XX um olhar mais plural de feminismo se estabeleceu. Por isso, a terceira onda feminista inicia com os questionamentos propostos pela segunda fase, no entanto, indagando a construção de mulher "universal", surgindo novas epistemologias feministas, como por exemplo, a partir das especificidades da realidade Latino-americana.

Nessa senda, a partir disso, introduziu-se um caminho para questionar a dicotomia entre o público e o privado, a objetificação da mulher e, sobretudo questionar a construção social de gênero. Essa fase é essencial para entender que a divisão social existente entre homem e mulher, forte e fraco, ríspido e sensível, nada mais é do que uma construção da modernidade que serviu como importante sustentação à ordem patriarcal.

Atualmente, na Sociedade em Rede, mulheres se unem para denunciar as violências sofridas e as nítidas desigualdades sociais, interseccionadas com outros eixos de dominação e exploração. De acordo com os autores analisados nesta pesquisa são os próprios agentes, as 
pessoas e os movimentos que decidem o que querem publicar na rede. Por isso, o feminismo contemporâneo emerge na era digital e está diretamente ligado às demandas das pessoas das regiôes periféricas do ocidente.

Assim, o feminismo enfrenta uma série de desafios para abranger a pluralidade e especificidade das diferentes mulheres, nas mais diversas áreas, pois, inicialmente o movimento feminista surge com demandas específicas de um grupo de mulheres que reivindicava direitos individuais e políticos na sociedade patriarcal que, insistentemente, via na mulher um sujeito a ser tutelado.

Desse modo, analisou-se, como o brechó itinerante e virtual, idealizado por mulheres poderia contribuir para apontar mudanças de desenvolvimento sustentável, que perpassam pela Teoria de gênero, Ecofeminismo, Sociedade em Rede e Sustentabilidade.

Nesse sentido, o "Brechados" expressa a intenção do feminismo na Sociedade em Rede e do Ecofeminismo. Uma vez que, além de estar ligado ao empoderamento e emancipação feminina, por meio do comprometimento com empreendedorismo através da rede, traz em sua essência a cooperação, auxílio e a empatia com outras mulheres empreendedoras e a preocupação com a degradação do meio ambiente à luz da Sustentabilidade.

Tais elementos são fundamentais para o movimento de mulheres e para a Sociedade em Rede, que nem sempre apresenta aspectos positivos, mas nesse caso, visualizou-se um cenário de pluralidade e emancipação.

O que compreende-se, através do estudo, é que a essência do Brechó contribui para mudanças de desenvolvimento sustentável, centrando-se na questão do empoderamento feminismo, cidadania e Sustentabilidade. Assim, por intermédio da experiência prática, buscam uma transformação na mentalidade e no comportamento da sociedade, visando a construção de uma consciência ecológica e com o empoderamento feminino, que chega a ser profunda, pelo engajamento, concentrada não só nos seus interesses próprios, mas de outras mulheres trabalhadoras, para propagar o propósito do Brechó e do (Re)uso de peças de roupas, acessórios e calçados, através de eventos, feiras na cidade e parcerias na própria loja, mobilizando através da rede e, assim valorizando o trabalho e empoderamento de outras obreiras.

Portanto, devem ser deslocadas as formas socialmente convencionadas, para trazer mudanças significativas, inteligentes e criativas como o "Brechados", e que sejam construídas através de pontes de diálogo, capazes de interligar essas lutas do movimento de mulheres, interseccionados com outros eixos de dominação e exploração. Certamente, o grande o desafio da Sociedade em Rede, e do Feminismo, nesse momento, é o de náo enxergar muros que nos separam, mas ligaçóes em comum, proporcionando deslocamentos e formas de mudanças, de respeito às diferenças, articulando em conjunto e retornando a uma unidade original com a natureza, cuidado e, sobretudo de respeito com o próximo e com toda a biodiversidade do planeta. 


\section{REFERÊNCIAS}

ANGELIN, Rosângela. Mulheres, ecofeminismo e desenvolvimento sustentável diante das perspectivas de redistribuição e reconhecimento de gênero. Estamos preparados?. Revista Eletrônica Direito e Política, Programa de Pós-Graduação Stricto Sensu em Ciência Jurídica da UNIVALI, Itajaí, v.9, n.3, 30 quadrimestre de 2014. Disponível em: www.univali.br/ direitoepolitica - ISSN 1980-7791. Acesso em: 30 out. 2019.

ARRUZZA, Cinzia; BHATTACHARYA, Tithi; FRASER, Nancy. Feminismo para os 99\%: Um manifestoTradução de Heci Regina Candiani. São Paulo: Boitempo, 2019.

BAUER, C. (2001). Breve História da mulher no mundo ocidental. São Paulo: Xamâ: Edições Pulsar.

BAUMANN, Zygmunt. Globalização: as consequências humanas. Tradução de Marcus Penchel. Rio de Janeiro: Zahar, 1999.

CAPRA, Fritjof. A teia da vida. Uma nova compreensão científica dos sistemas vivos. Editora Cultrix. São Paulo. 1996.

CASTELLS, Manuel. A sociedade em rede. 11. ed. Traduzido por Roneide Venâncio Majer. São Paulo: Paz e Terra, 1999. v. 1.

CASTELLS. O poder da comunicaçáo/Manuel Castells; tradução de Vera Lúcia Mello Joscelyne; revisão de tradução de Isabela Machado de Oliveira Fraga.- $1^{\text {a }}$ ed.- São Paulo/Rio de Janeiro: Paz e Terra, 2015.

CONNELI, Raewyn; PEARSE, Rebecca. Gênero: uma perceptiva global. São Paulo: NVersos, 2015.

DAVIS, Angela. Mulheres, raça e classe. Traduzido por Heci Regina Cadiani. São Paulo: Boitempo, 2016. Título original: Women, race and class.

FEDERICI, Silvia. O calibã e a bruxa. Mulheres, corpo e acumulaçáo primitiva. São Paulo: Editora Elefante (tradução Sycoraux), 2017.

FREITAS, Juarez. Sustentabilidade: Direito ao Futuro. 3a ed., BH: Fórum, 2016.

HIRATA, Helena et al. (Org.). Dicionário Crítico do Feminismo. São Paulo: Editora UNESP, 2009.

JUNGES, José Roque. Bioética ambiental. São Leopoldo, RS : Editora UNISINOS, 2010, $144 \mathrm{p}$.

LÉVY, Pierre. Ciberdemocracia. Lisboa: Instituto Piaget, 2002.

LÉVY, Pierre. Cibercultura. (Trad. Carlos Irineu da Costa). São Paulo: Editora 34, 1999. 
MIGUEL, Luis Felipe, BIROLI, Flávia. Feminismo e política: uma introdução. 1.ed. São Paulo: Boitempo, 2014.

OLSEN, Frances. El sexo del derecho. Publicado em David Kairys (ed.), The Politicsof Law (Nueva York, Pantheon, 1990), pp.452-467. Traduçâo para espanhol de Mariela Santoro y Christian Courtis. Disponível em <http://www.derechoshumanos.unlp.edu.ar/assets/files/ documentos/el-sexo-del-derecho.pdf> Acesso em: 30 out. 2019.

RIBEIRO, Djamila. O que é lugar de fala? Belo Horizonte (MG): Letramento, 112 páginas, 2017. (Coleção: Feminismos Plurais)

SAFFIOTI, Heleieth. Contribuiçóes feministas para o estudo da violência de gênero. Disponível em: <http:|lwww.unb.br/ih/his/gefem/heleieth1.html>. Acesso em junho de 2019.

SHIVA, Vandana. Abrazar la vida: Mujer, ecologia y supervivencia. 1998. Disponível em <https://observatorio.aguayvida.org.mx/media/vandana-shiva-abrazar-la-vida.-mujer-ecologiay-supervivencia.pdf>. Acesso em Junho de 2019.

SILIPRANDI, Emma. Ecofeminismo: contribuiçóes e limites para a abordagem de políticas ambientais. Agroecol. E Desenv. Rur. Sustent., Porto Alegre, c. 1, n1, jan./mar. 2000. Disponível em <http://taquari.emater.tche.br/docs/agroeco/revista/n1/11_artigo_ ecofemi.pdf>. Acesso em: 30 out. 2019.

SILVA, Tomaz Tadeu da (Org.). Identidade e diferença: a perspectiva dos estudos culturais. 9. ed. Rio de Janeiro: Vozes, 2009.

SILVA, Jacilene Maria. Feminismo na atualidade: a formação da quarta onda. 1. Ed. Recife: Independently Published, 2019.

SANTOS, Paloma Maria; BERNARDES, Marciele Berger; ROVER, Aires José. Teoria e Prática de Governo Aberto: Lei de Acesso à Informação nos Executivos Municipais da Regiáo Sul. Florianópolis: Fundação Boiteux, 2012.

VOLKMER, André. A democracia na era digital. In: INSTITUTO DE ESTUDOS EMPRESARIAIS. Liberdade na era digital. Porto Alegre: IEE, 2011, p. 90-109.

VELOSO, Renato. Tecnologias da informaçáo e comunicaçáo: desafios e perspectivas. São Paulo: Saraiva, 2011. 